- Bleaching gels activated by Diode lasers in Power Bleaching act as effective insulators, helping prevent large increases in temperatures within the pulp chamber.

- Teeth should never be directly irradiated with laser energy without the presence of the bleaching gel.

- Temperature rises within the pulp chamber reduce to baseline levels very quickly after removal of laser irradiation.

- Diode lasers used to activate bleaching gels are not considered dangerous to the vitality of dental pulps using power settings of up to $2 \mathrm{~W}$.

\title{
Surface and pulp chamber temperature rises during tooth bleaching using a diode laser: a study in vitro
}

\author{
M. Sulieman, ${ }^{1}$ J. S. Rees ${ }^{2}$ and M. Addy ${ }^{3}$
}

\begin{abstract}
Objective To measure the surface and pulp chamber temperature increases in vitro on upper and lower anterior teeth during a tooth whitening procedure using a diode laser.
\end{abstract}

Method A thermocouple was used to measure the temperature increase on the surface of an extracted upper central incisor tooth. Pulp chamber temperature readings were made on upper and lower central incisors, lateral incisors and canines. A diode laser recommended for tooth bleaching was tested at three different power settings ( $1 \mathrm{~W}, 2 \mathrm{~W}, 3 \mathrm{~W})$. Temperature measurements were made with and without the bleaching agent present on the labial tooth surface.

Results The increase in surface temperature readings ranged from $37^{\circ} \mathrm{C}(1 \mathrm{~W})$ to $86.3^{\circ} \mathrm{C}(3 \mathrm{~W})$ with no bleaching gel present. Pulp chamber temperature increases ranged from $4.3^{\circ} \mathrm{C}(1 \mathrm{~W})$ to $16^{\circ} \mathrm{C}(3 \mathrm{~W})$. The presence of the bleaching gel reduced temperature increases seen at the tooth surface and within the pulp.

Conclusions The increase in the pulp chamber temperature with the laser used at 1-2W was below the critical temperature increase of $5.5^{\circ} \mathrm{C}$ thought to produce irreversible pulpal damage. However, a power setting of $3 \mathrm{~W}$ produced a pulp chamber temperature increase above this threshold $\left(16^{\circ} \mathrm{C}\right)$ and caution is advised when using this setting.

\section{INTRODUCTION}

Tooth whitening continues to grow in popularity and the desire for whiter teeth has reached an all time high, with many articles featured in the popular press and on television on a regular basis. This has resulted in renewed interest from the profession in the variety of bleaching techniques available, as they are essentially non-invasive and simple to carry out. Contemporary bleaching systems are based primarily on hydrogen peroxide (HP) or one of its precursors, notably carbamide peroxide (CP), and these

\footnotetext{
1, ${ }^{* 3}$ Division of Restorative Dentistry, Department of Oral \& Dental Science, University of Bristol Dental School, Lower Maudlin Street, Bristol, BS1 2LY; ${ }^{2}$ Adult Dental Health Department, Dental School, University of Wales College of Medicine, Heath Park, Cardiff, CF4 4XY

${ }^{*}$ Correspondence to: Dr Munther Sulieman

Email:m.sulieman@bristol.ac.uk
}

\section{Refereed paper}

Accepted 15 June 2005

DOI: $10.1038 /$ sj.bdj.4813644

๑) British Dental Journal 2006; 200: 631-634 materials are often used in combination with an activating agent such as heat or light. ${ }^{1-2}$

Many in-surgery power bleaching systems are based on HP using concentrations of up to 35\% applied as a gel to the tooth surface. An activating light source is then applied to the tooth surface to increase the reaction rate and accelerate the decomposition of HP to oxygen and per-hydroxyl free radicals, which are thought to bleach the teeth. Most lights used to accelerate the decomposition process also generate heat. Concerns have been expressed about using light as part of the bleaching process as the heat generated by the lamp could potentially lead to pulpal necrosis. ${ }^{2}$ Zach and Cohen $^{3}$ related known surface temperature increases to histologically observable pulpal injury after periods of two, 14, 56 and 91 days in Rhesus monkeys. A soldering iron heated to $275^{\circ} \mathrm{C}$ was applied to the buccal surface of healthy teeth until the required temperature had been reached at the pulp wall. They found that $15 \%$ of teeth heated by $5.5^{\circ} \mathrm{C}$ and $60 \%$ of teeth heated by $11.1^{\circ} \mathrm{C}$ suffered irreversible damage. However, these threshold values for irreversible pulpal damage have been questioned by some workers who suggest that these values should be higher., ${ }^{4,5}$

The effects of various lights used to accelerate the in-surgery power bleaching procedures on surface and pulp chamber temperature rises has been investigated previously. ${ }^{6}$ It was found that the increase in the pulp chamber temperature with most bleaching lamps was below the critical threshold of a $5.5^{\circ} \mathrm{C}$.

With the uncertain legal situation within the European community and especially within the UK, it has become important to investigate the various safety aspects of bleaching.

The aim of this in vitro study was to examine the heat generated by the different power settings of a commercially available diode laser used for vital bleaching. It was intended to provide safety parameters for this equipment, which like all lights currently available for bleaching procedures is approved by the FDA under a grandfather clause without individual lights being tested.

\section{MATERIALS AND METHOD}

A diode laser (Medivance Instruments Ltd, Barretts Green Road, Harlesden, London NW10 7AP) with a spectral wavelength in the near infra-red region of 830nm was used in the study. The power outputs used ranged between $1 \mathrm{~W}$ and $3 \mathrm{~W}$.

The procedures employed have been described previously. ${ }^{6}$ The temperature increase produced by the diode laser was 


\begin{tabular}{|c|c|c|c|}
\hline Power setting & Minus Gel & Plus Gel & Significance \\
\hline $1 \mathrm{~W}$ & $37.0(1.78)$ & $5.23(0.85)$ & $P<0.0001$ \\
\hline $2 W$ & $64.1(2.01)$ & $7.74(0.55)$ & $P<0.0001$ \\
\hline $3 \mathrm{~W}$ & $86.3(3.40)$ & $11.6(1.34)$ & $P<0.0001$ \\
\hline
\end{tabular}

Table 2 Pulpal temperature increase from baseline $\left({ }^{\circ} \mathrm{C}\right)$ without gel [SD in parentheses]

\begin{tabular}{l|l|l|l|l|l|l}
\hline $\begin{array}{l}\text { Power } \\
\text { setting }\end{array}$ & \multicolumn{2}{|l|}{ Upper teeth } & \multicolumn{2}{l}{ Lower teeth } \\
\hline & Central & Lateral & Canine & Central & Lateral & Canine \\
\hline \multirow{2}{*}{1 W } & 4.5 & 5.7 & 4.3 & 5.9 & 6.7 & 4.5 \\
& $(0.34)$ & $(1.06)$ & $(0.41)$ & $(0.18)$ & $(0.29)$ & $(0.36)$ \\
\hline \multirow{2}{*}{$2 W$} & 7.5 & 10.5 & 7.3 & 10.5 & 10.5 & 7.4 \\
& $(0.23)$ & $(0.35)$ & $(0.47)$ & $(0.23)$ & $(0.17)$ & $(0.36)$ \\
\hline \multirow{2}{*}{$3 W$} & 10.7 & 15.6 & 10.6 & 15.7 & 15.9 & 10.6 \\
& $(0.52)$ & $(0.36)$ & $(0.41)$ & $(0.34)$ & $(0.13)$ & $(0.22)$ \\
\end{tabular}

measured with a K type thermocouple with a positive nickelchromium arm and a negative nickel-aluminium arm. A change in temperature between the junction of the two alloys produced a voltage that is proportional to the temperature rise; this is known as the Seebeck effect.

The voltage generated was fed into an eight channel data logger (PICO TC-08; Pico Technology Ltd, The Mill House, Cambridge Street, Neots, Cambridgeshire, PE 1QB) connected to a laptop computer. The thermocouple produced a voltage of $40 \mu \mathrm{V}$ per degree Celsius. This signal was amplified by the data logger and fed into a 16-bit analogue to digital converter. The data were sampled once every 40 msecs and this was fed into the Pico Log data-logging programme (Pico Technology Ltd, The Mill House, Cambridge Street, Neots, Cambridgeshire, PE 1QB) for Windows. This is a flexible data-logging package for collecting, analysing and displaying data.

The teeth employed were an upper and lower central incisor, lateral incisor and canine. All teeth had been sectioned $2 \mathrm{~mm}$ below the level of the amelo-cemental junction to allow for easy access of the thermocouple which was held in place using red wax. Measurements were made either on the tooth surface or within the pulp chamber, at room temperature with and without the presence of the bleaching gel on the tooth surface. Pulpal measurements were made by placing the thermocouple at the most coronal level of the pulp chamber and its position was checked using radiography. The teeth were irradiated for 30 seconds with the diode laser at power settings of $1 \mathrm{~W}, 2 \mathrm{~W}$ or $3 \mathrm{~W}$ according to the manufacturer's instructions. Each measurement was repeated six times for each power setting on each tooth type.

The allocation of different power settings (1-3W) to tooth type was randomised using a random allocation table and at least 30 minutes was allowed between replicate applications of the same and between power settings. The return of the temperature to ambient temperature was checked by reference to the thermocouple reading. For the surface measurements, it was established from a previous study that tooth type did not influence the temperature rise. ${ }^{6}$ The surface study was therefore carried out using the upper central incisor only with six readings taken for each power setting with and without bleaching gel. The same 30 minute period was allowed between readings with the same or between power settings.

Approximately $0.5 \mathrm{ml}$ of freshly mixed bleaching gel was applied to cover the labial surface of the test teeth. The bleaching agent (Opus mix bleaching powder, Transchem Ltd, 205 Gunnersbury Lane, Acton W3 8LJ) was prepared by mixing together $0.1 \mathrm{gm}$ of the bleaching powder, containing fumed silica, blue photoactive colorants and dyes, with $0.5 \mathrm{ml}$ of 35\% HP liquid. The mixture was then applied to the enamel surface of the specimen to produce a uniform layer approximately $2 \mathrm{~mm}$ thick. The mixture was activated with the handpiece of the diode laser placed just above the surface of the gel (Fig. 1). The gel was removed and a fresh mix of gel placed for each subsequent temperature reading. That is, there were a total of 108 gel applications for the pulp chamber study and 24 for the surface study.

The dentine thickness at the horizontal cut surface of the tooth, which was just below the level of the amelocemental junction, was measured using electronic calipers accurate to $0.01 \mathrm{~mm}$ (Mitutoyo (UK) Ltd, West Point Business Park, Andover, Hampshire). Measurements were made from the pulpal dentine surface to the external root surface. Six measurements were made per specimen and a mean result reported.

\section{STATISTICAL METHODS}

The surface temperature readings with and without the bleaching gel were compared using a two-tailed student's ' $t$ ' test with a significance threshold set at 0.05 . This was repeated for all three power settings. The pulpal temperature readings for the six tooth types were compared using analysis of variance followed by a Tukey's test with a significance threshold set at 0.05 . This was repeated for each power setting and for the results where the bleaching gel was applied to the tooth surface and when omitted.

\section{RESULTS}

\section{Surface study}

The mean and standard deviations of the temperature rise at the incisor surface using the laser at $1 \mathrm{~W}, 2 \mathrm{~W}$ and $3 \mathrm{~W}$ with and without gel are shown in Table 1. The temperature increases ranged from $7.7^{\circ} \mathrm{C}$ to $86.3^{\circ} \mathrm{C}$ and observationally the temperature rise followed the power settings in that the smallest and largest rises with and without gel were seen with $1 \mathrm{~W}$ and $3 \mathrm{~W}$ settings respectively. The gel appeared to provide considerable insulation at all the settings and temperature rises were greatly reduced. The results of the surface temperature readings with and without the gel were highly significantly different $(\mathrm{P}<0.0001)$.

\section{Pulp chamber study}

The mean and standard deviation of the temperature rises in the pulp chambers of the test teeth at each power setting with and without gel are shown in Tables 2 and 3. Observationally, there are mean differences in temperature rises between the three potential variables of tooth type, power setting and gel use. Tooth type without gel for each power setting shows that the upper central incisor, upper and lower canines have similar temperature rises. In most cases upper central and lateral incisors had lower temperature rises compared to lower central and lateral incisors.

When gel was added, similar effects of tooth type can be seen but with smaller mean differences between upper and lower incisors at each power setting. Both with and without gel, differences between power settings are clearly apparent with the smallest temperature rise recorded with the laser set at $1 \mathrm{~W}$ and greatest with the laser set at $3 \mathrm{~W}$.

The temperature rise falls to 50\% within 20 seconds after removing the laser irradiation and then takes a further 150 seconds to reach baseline levels. The variation of power settings made no difference to the temperature fall following removal of the laser irradiation and the pattern of heat dissipation was the same for all readings. The maximum temperatures recorded within the pulp chamber ranged from $16.6^{\circ} \mathrm{C}$ to $23.5^{\circ} \mathrm{C}$ at $1 \mathrm{~W}, 19.6^{\circ} \mathrm{C}$ to $24.7^{\circ} \mathrm{C}$ at 2W and $21.1^{\circ} \mathrm{C}$ to $25.6^{\circ} \mathrm{C}$ at $3 \mathrm{~W}$.

The gel appeared to provide an insulating effect and temperature rises were minimised in all teeth across all settings when gel 
was present. At a power setting of $1 \mathrm{~W}$ without bleaching gel, the pulp chamber temperature readings for the upper central incisor was found to be significantly different from that of the upper lateral $(\mathrm{P}<0.05)$ and lower central incisors $(\mathrm{P}<0.01)$. Similarly, the readings of the upper lateral incisor were significantly different to the upper canine $(\mathrm{P}<0.01)$ and the lower central and lateral incisors were significantly different from the lower canine $(\mathrm{P}<0.01$ and $\mathrm{P}<0.001$ respectively).

In addition to the differences seen at $1 \mathrm{~W}$, there were equally significant differences seen at $2 \mathrm{~W}$ between the upper central and lower lateral incisor $(\mathrm{P}<0.001)$, upper canine and lower central incisor $(\mathrm{P}<0.001)$.

At $3 \mathrm{~W}$ the temperature readings of the upper central incisor was found to be significantly different from the upper lateral incisor $(\mathrm{P}<0.01)$ which was in turn significantly different from both the upper canine and lower central incisor $(\mathrm{P}<0.05$ and $\mathrm{P}<0.01$ respectively)

The results of the variation in dentine thickness are shown in Table 4 . The values for the lower canine were significantly different from the lower central incisor $(p<0.01)$ and from the lower lateral incisor $(\mathrm{p}<0.05)$. There were no statistically significant differences between the upper anterior teeth.

\section{DISCUSSION}

This study has reported the surface and pulpal temperature readings found on upper and lower anterior teeth during simulated vital tooth bleaching using a diode laser at various power settings. As in a previously reported study, ${ }^{6}$ the surface readings were found to be much higher than the pulpal readings. This is a consequence of the relatively low values for the thermal conduction of tooth tissue (coefficient of thermal conductivity), particularly dentine $\left[1.36 \times 10^{-3} \mathrm{cal} \mathrm{sec}^{-1} \mathrm{~cm}^{-2}\right] .^{7}$ The consequence of this is that the transmission of heat in teeth occurs at a relatively slow rate. ${ }^{8}$

\section{Surface study}

The diode laser at $3 \mathrm{~W}$ without gel produced the highest surface temperature change at $86^{\circ} \mathrm{C}$ compared to $37^{\circ} \mathrm{C}$ at $1 \mathrm{~W}$ which was to be expected (Table 1). The addition of the bleaching gel greatly reduced the temperature rise at all power settings by

Table 3 Pulpal temperature increase from baseline $\left({ }^{\circ} \mathrm{C}\right)$ with gel [SD in parentheses]

\begin{tabular}{l|l|l|l|l|l|l}
\hline $\begin{array}{l}\text { Power } \\
\text { setting }\end{array}$ & \multicolumn{2}{|l|}{ Upper teeth } & \multicolumn{2}{l}{ Lower teeth } \\
\hline & Central & Lateral & Canine & Central & Lateral & Canine \\
\hline \multirow{2}{*}{ CW } & $\begin{array}{l}3.1 \\
(0.06)\end{array}$ & $\begin{array}{l}4.0 \\
(0.35)\end{array}$ & $\begin{array}{l}3.2 \\
(0.39)\end{array}$ & $\begin{array}{l}3.2 \\
(0.22)\end{array}$ & $\begin{array}{l}3.4 \\
(0.27)\end{array}$ & $\begin{array}{l}3.3 \\
(0.39)\end{array}$ \\
\hline \multirow{2}{*}{$2 \mathrm{~W}$} & $\begin{array}{l}5.2 \\
(0.32)\end{array}$ & $\begin{array}{l}6.8 \\
(0.31)\end{array}$ & $\begin{array}{l}5.6 \\
(0.41)\end{array}$ & $\begin{array}{l}6.4 \\
(0.43)\end{array}$ & $\begin{array}{l}6.5 \\
(0.85)\end{array}$ & $\begin{array}{l}5.3 \\
(0.36)\end{array}$ \\
\hline \multirow{2}{*}{ Laser } & $\begin{array}{l}7.1 \\
(0.46)\end{array}$ & $\begin{array}{l}8.5 \\
(0.28)\end{array}$ & $\begin{array}{l}7.1 \\
(0.31)\end{array}$ & $\begin{array}{l}8.7 \\
(0.79)\end{array}$ & $\begin{array}{l}8.6 \\
(0.64)\end{array}$ & $\begin{array}{l}7.1 \\
(0.28)\end{array}$ \\
\hline
\end{tabular}

Table 4 Cervical dentine thickness

\begin{tabular}{l|l|l}
\hline Tooth & Mean thickness $(\mathrm{mm})$ & Standard Deviation \\
\hline Upper central incisor & 2.33 & 0.40 \\
\hline Upper lateral incisor & 1.58 & 0.49 \\
\hline Upper canine & 2.16 & 0.51 \\
\hline Lower central incisor & 1.16 & 0.25 \\
\hline Lower lateral incisor & 1.41 & 0.66 \\
\hline Lower canine & 2.25 & 0.41
\end{tabular}

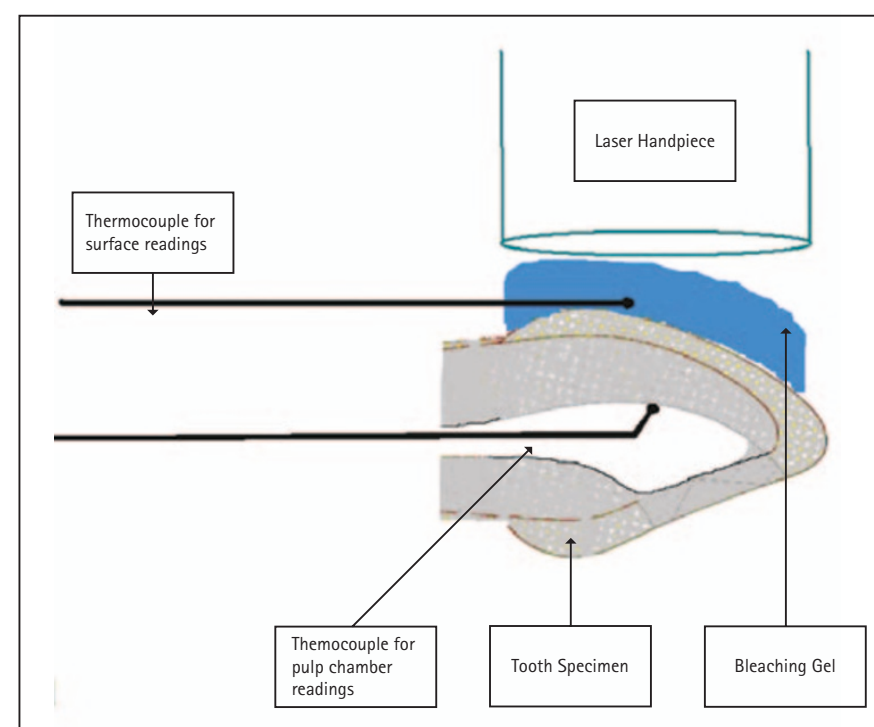

Fig. 1 Experimental setup of tooth with placement of thermocouples and laser handpiece.Thermocouple for pulp chamber readings

86-88\%, thereby affording an effective insulating layer to the tooth. The presence of HP and water in the gel could provide a further potential cooling effect upon evaporation of these components from the tooth surface.

The insulating effects of the gel produced greatly reduced temperature rises of $5.2^{\circ} \mathrm{C}$ at $1 \mathrm{~W}$ compared to $11.6^{\circ} \mathrm{C}$ at $3 \mathrm{~W}$ with the laser set at its upper limit for bleaching.

\section{Pulp chamber study}

The increase in pulp chamber temperatures with the three power settings followed a similar pattern as the surface temperature increased. Without the bleaching gel, the increase in the pulpal temperature of the laser at $1-3 \mathrm{~W}$ ranged from $4.3-16^{\circ} \mathrm{C}$ with the smallest temperature increases in the central upper incisor, upper and lower canines. The smallest temperature increases in these teeth can presumably be attributed partly to the thickness of dentine compared to the thinner upper lateral, lower central and lateral incisors. The simple measurements of the dentine thickness found that the dimensions of the lower central and lateral incisors were significantly different from the lower canine. No statistical differences between the upper teeth were found. However, these measurements were only made in a single plane, just below the amelocemental junction. In reality, the dentine thickness within a tooth will vary depending on the rate at which secondary and tertiary dentine is laid down.

With the bleaching gel present the temperature rise recorded for the laser at 1-2W was for the most instances within or close to the critical temperature suggested by Zach and Cohen, ${ }^{3}$ but the temperature increase with the laser diode at $3 \mathrm{~W}$ was significantly greater at $8.8^{\circ} \mathrm{C}$. The tendency for temperature increases to be greater in the upper and lower lateral incisors, was again present.

Zach and Cohen ${ }^{3}$ found in a monkey model that a $5.5^{\circ} \mathrm{C}$ temperature rise was likely to cause irreversible pulpal damage when used on its maximum setting. However, these threshold values have been questioned by some workers ${ }^{4,5}$ who suggest that they should be higher. Baldissara et al..$^{5}$ demonstrated that an intra-pulpal temperature rise between $8.9^{\circ} \mathrm{C}$ and $14.7^{\circ} \mathrm{C}$ in humans did not produce pulpal pathology and hypothesised that the post-operative sensitivity seen clinically was the result of modification of the dentine. However, if the threshold value of $5.5^{\circ} \mathrm{C}$ is applied to our data then the power setting of $3 \mathrm{~W}$ may be capable of causing pulpal damage, but 1-2W are unlikely to have any adverse effects on the pulp. 
One must also take into account the effect of an intact pulpal blood flow, which will act as an efficient heat sink, with the pulpal circulation being able to dissipate some of the applied heat before pulpal cells are damaged. ${ }^{9}$ The current in vitro model was not able to replicate this, so it is possible that the $8.8^{\circ} \mathrm{C}$ pulp chamber temperature rise recorded for the laser at $3 \mathrm{~W}$ with lower incisors could, in reality, be less and therefore below the threshold for irreversible damage. Furthermore, the natural flow of fluid from the pulp and through the enamel and dentine was not simulated and this flow could also impede the transfer of heat to the pulpal tissues. Other shortfalls in interrupting the results of this study is that, apart from the surface experiment, this type of study could not be conducted in vivo. Even a study in vivo on teeth undergoing root canal therapy would be less representative of the clinical situation than the present in vitro model. In a clinical study the thermocouple would not be totally enclosed in tooth tissues as it would be introduced through a coronal access cavity and there would be heat loss to the surrounding air introducing a potentially significant error. Other workers have investigated pulp chamber temperature changes during light activated vital tooth bleaching using a model that simulated blood flow through the tooth. ${ }^{10}$ In that study, water was infused through the tooth at a rate similar to physiological blood flow using an inlet tube through the root of the tooth and an outlet tube through the lingual surface of the crown of the tooth. However, a question must be raised to the degree of replication to the actual in vivo clinical situation where the blood flow in and out is via the totally enclosed root.

This study was conducted to further investigate the potential for pulpal damage using a diode laser and to provide safety parameters for the use of this device. The potential for pulpal damage using a power setting of $3 \mathrm{~W}$ is much greater than $1-2 \mathrm{~W}$.

In conclusion, this study has shown that the use of a bleaching gel is able to offer a protective insulating layer against the surface and pulpal temperature increases that accompany the use of a diode laser for bleaching, but caution should be exercised in the use of power settings of $3 \mathrm{~W}$ to activate the bleach, particularly if it is used over extended time periods. Power settings of $1-2 \mathrm{~W}$ are within the safety parameters for the use of this device in activating the bleaching agent. In addition, these settings are more than enough in accelerating the bleaching process by causing the breakdown of the HP gel to reactive free radicals that penetrate the tooth to cause the oxidation of stain molecules within the tooth structure.

1. Clinical Research Associates. New generation in-office vital tooth bleaching Part 2. CRA Newsletter 2003; 27: 1-2

2. Tjan A H L, Dunn J R. Temperature rise produced by various light generators through dentinal barriers. J Prosthet Dent 1988; 59: 433-438.

3. Zach L, Cohen G. Pulp response to externally applied heat. Oral Surg Oral Med Oral Path 1965; 19: 515-530.

4. Lloyd C H, Joshi A, McGlynn E. Temperature rise produced by light sources and composites during curing. Dent Mats 1986; 2: 170-174.

5. Baldissara P, Catapano S, Scotti R. Clinical and histological evaluation of thermal injury thresholds in human teeth: preliminary study. J Oral Rehabil 1997; 24: 791-801.

6. Sulieman $M$, Addy $M$, Rees J S. Surface and intra-pulpal temperature rises during tooth bleaching: a study in vitro. Br Dent J 2005; 199: 37-40.

7. Craig R G, Peyton FA. Thermal conductivity of tooth structures, dentine, cements and amalgam. J Dent Res 1961, 40: 411-418.

8. Longman C M, Pearson G J. Variations in tooth surface temperature in the oral cavity during fluid intake. Biomats 1987; 8: 411-414

9. Goodis $H$ E, White J E, Andrews J, Wanatabe L G. Measurement of temperature generated by visible light cure lamps in an in vitro model. Dent Mats 1989, 5: 230-234.

10. Baik J W, Rueggeberg F A, Liewehr F R. Effect of light enhanced bleaching on in vitro surface and intrapulpal temperature rise. J Esthet Restor Dent 2001; 13:370-378. 